\title{
Speculative cartography and the formation of public interest issues
}

\section{SIGRADI2018 TECHNOPOLITICAS \\ xxii congresso da sociedade iberoamericana de gráfica digital 22th conference of the iberoamerican society of digital graphics 07|08|09|novembro|2018 iau usp | são carlos | sp br}

\author{
Clorisval Pereira Jr. \\ PUC-Rio | Brazil | cjunior@gmail.com
}

\begin{abstract}
This work discusses how locative media and the democratization of geoprocessing technologies have reconfigured our experience with the urban space, opening up new territories for the construction of the public. It also discusses perspectives and challenges that speculative practices with locative media bring to disciplines such as design, architecture and engineering, and to the production of more sustainable ways of life. For that matter, this work presents some experiments with locative media and digital cartographies that aim to give visibility to our social relation with the urban space and to support processes of sensemaking about issues of public interest.
\end{abstract}

Keywords: Locative media; Critical cartography; Social cartography; Speculative design.

\section{INTRODUÇÃO}

Diversos autores vem chamando atenção para os processos de hibridização do espaço físico com o espaço digital (Souza e Silva, 2006) e para a formação de novos espaços públicos nesses territórios onde nossas interações com o espaço físico são cada vez mais mediadas por tecnologias da informação e comunicação (McQuire, 2006; Hemment e Thompson, 2013).

Neste contexto, é importante observar como diferentes práticas ativistas com tecnologias de geolocalização vêm abrindo novos territórios culturais e políticos de construção da coisa pública. Nesse caso, é importante destacar a emergência das práticas artísticas com mídias locativas (Lemos, 2008) e a democratização das tecnologias de geoprocessamento, e sua convergência as tecnologias de Internet, que abriram novos campos de exploração crítica das tecnologias de mapeamento e produção cartográfica (Cramptom, 2009).

Santaella (2008) observa como explorações artísticas com mídias locativas carregam uma proposta estética política que remete tanto a um legado de práticas ativistas e críticas no campo da arte como a land art, os happenings e com a psicogeografia dos situacionistas, como também com as teorias urbanas radicais de Henri Lefebvre e Jane Jacobs. Para a autora, o campo da arte tem um papel de "tomar a dianteira da criação cultural, fazendo emergir complexidades que, sem a arte, não teríamos capacidade de enxergar" (Santaella, 2008 p.133).

As práticas com mídias locativas exploram antes de mais nada como a computação pervasiva e as tecnologias digitais geolocalizas, e em rede, mediam cada vez mais a nossa relação social com o espaço físico. Neste sentido, estas práticas tem explorado diferentes tecnologias para geolocalizar dados, informações, anotações e narrativas digitais, bem como para mapear rastros, percursos e fluxos de pessoas e dados no espaço urbano (Tuters e Varnelis, 2006; Lemos, 2008).

Apesar de críticas ao fato de que as mídias locativas se utilizam em grande parte de tecnologias que servem a interesses de controle e vigilância, sejam militares ou comerciais, diversos autores defendem que grande parte das práticas artísticas com mídias locativas caracterizam justamente formas de resistência às tecnologias mercadológicas, uma vez que subvertem e "hackeiam" essas tecnologias se valendo de práticas abertas, colaborativas e críticas, redirecionando o poder inerente a essas tecnologias (Santaella, 2008).

Por outro lado, também é importante observar como toda uma nova geração de tecnologias geoespaciais trouxeram uma nova energia para o campo da cartografia crítica e social. Para Crampton (2010), a democratização das tecnologias de informação geográfica "indisciplinaram" as práticas de mapeamento levando-as além das mãos de especialistas e acadêmicos, para além dos métodos científicos positivistas e cartesianos, possibilitando a exploração de novos mundos e de sociedades em devir, alinhada a toda uma tradição de cartografia crítica que tensiona e questiona as narrativas de poder associadas à produção de mapas.

Ao refletir sobre as grandes mudanças tecnológicas e financeiras causadas pelo capitalismo no final do século XX, Fredric Jameson (1991) apontava para a necessidade de se inventar novas formas de representação e novas estéticas de mapeamento, que permitissem uma melhor compreensão de como o nosso posicionamento individual e coletivo na sociedade que está se redefinindo cada vez mais rápido em termos de redes sociais e redes de comércio. 
Jameson questionou a nossa capacidade de imaginar e elaborar alternativas ao modelo de produção industrial capitalista baseado em redes globalizadas de consumo. As práticas com mídias locativas e de cartografia crítica exploram justamente novas estéticas e novas formas de representação das nossas relações sociais com esses esses territórios de fluxos e podem apoiar processos de construção de sentidos sobre a coisa pública.

Neste sentido, entendemos que essas práticas ativistas, críticas e especulativas com mídias locativas e com cartografias digitais trazem alguns desafios interessantes para o campo do design e das disciplinas centradas na cultura do projeto, como a arquitetura e a engenharia. Essas práticas dão visibilidade às tramas que constituem as nossas relações sociais e espaciais e podem apoiar a construção de visões e protótipos de modos de vida mais sustentáveis. Além disso, essas práticas estimulam uma cultura de "hacktivismo", centrada em tecnologias abertas e colaborativas, que reforçam a importância da experimentação e da especulação nas disciplinas de projeto, propondo, de certa forma, uma indisciplina do projeto.

À medida em que crises ambientais, sociais e políticas se tornam cada vez mais complexas e imbricadas, torna-se cada vez mais importante investigar como o design pode apoiar estratégias de construção de sentidos sobre questões de interesse público.

Autores como Manzini (2015) e Irwin (2015), tem destacado a importância do design na produção de contextos de transição para modos de vida mais sustentáveis, associados a teorias de mudança e a culturas de compartilhamento de informação e conhecimento. Mais do que enfatizar expertises técnicas de solução de problemas, tradicionalmente privilegiadas no campo do design, os autores defender a importância de se desenvolver capacidades de produção de sentidos para tornar mais compreensíveis as questões sociais complexas que impactam nossa sociedade contemporânea.

Autores como Levy (1998) e Sestini (2012) defendem que as tecnologias digitais podem apoiar processos de produção de inteligências coletivas, que por sua vez possuem um papel fundamental na construção de sentidos sobre questões de interesse público.

Podemos entender processos de construção de sentidos sobre questões de interesse público como processos de construção da "coisa pública". DiSalvo (2009) discute a construção da coisa pública à luz do pensamento de Dewey e Latour. Dewey estava interessado em como a coisa pública é constituída, para poder investigar as potencialidades e condições que possibilitam ou inibem a ação política coletiva nos tempos contemporâneos. Na exposição e livro "Making Things Public: Atmospheres of Democracy", Latour e Weibel (2005) retomam as indagações de Dewey, e perguntam "Como as coisas são feitas públicas?" adicionando a questão complementar "Como o público é feito a partir das coisas?".

Para Dewey e Latour, a coisa pública é emergente, está em constante formação. E esse entendimento da coisa pública não pode estar dissociado da materialidade concreta dos fatos, situações e experiências da vida cotidiana. Através da Teoria Ator-Rede, Latour (2005) observa como o contexto sócio-material é formado por agregações emergentes de pessoas, objetos, coisas, que determinam as questões de fato e questões de interesse que formam a coisa pública.

Para DiSalvo (2009), uma forma do design contribuir com a construção da coisa pública seria através de táticas de rastreamento, que podem revelar e expor as estruturas subjacentes dessas agregações, dessas redes sóciomateriais, das ações, conceitos e valores que formam a coisa pública.

Em Pereira Jr. et al. (2016), analisamos diversas iniciativas de crowdmapping e mapeamento colaborativo que vem fazendo uso de tecnologias de informação geográfica para rastrear e representar questões de interesse público, bem como para promover engajamento cívico e comunitário.

Neste trabalho exploramos alguns experimentos com mídias locativas e cartografias digitais buscando entender como essas práticas podem dar visibilidade a questões de interesse público e ao mesmo tempo podem estimular uma cultura de projeto mais aberta, especulativa e crítica.

\section{METODOLOGIA}

Partindo de uma abordagem de pesquisa-ação, com ênfase em uma perspectiva de design crítico e especulativo (Dunne e Raby, 2013), propusemos explorar práticas de mapeamento utilizando mídias locativas, abordando contextos de cartografia crítica e social, envolvendo processos de geração cidadã de dados, e objetivando dar visibilidade a questões de interesse público.

Estes experimentos foram desenvolvidos como parte de pesquisa de doutorado em Design, no Departamento de Artes e Design da PUC-Rio, e inseridos nas atividades do Laboratório de Arte Eletrônica do Programa de Pósgraduação em Design da PUC-Rio (Pereira Jr., 2017).

Para o desenvolvimento dos experimentos foram adotadas duas táticas centrais da psicogeografia proposta pelos Situacionistas: a deriva e o desvio. A deriva, derivé, é antes de mais nada um comportamento lúdico-construtivo que propõe a construção de uma nova experiência com o espaço urbano a partir do rompimento com a racionalidade e com as estruturas dominantes da cidade (Debord, 1958). O desvio, détournment, ou redirecionamento, propõe uma apropriação de mídias e mecanismos mercadológicos, comumente utilizados pela sociedade de consumo, para uma subversão de mensagens e de informações (Debord e Wolman, 1956).

Nos mapeamentos realizados, procuramos romper com a estrutura dominante da grade urbana, buscando dar visibilidade a experiências com o espaço urbano que são carentes de enunciação. Ao mesmo tempo desviamos as funções de mídias sociais para produzir novas narrativas e mapeamentos da nossa experiência com a cidade.

Essa indisciplinaridade no uso das técnicas de mapeamento pode ser associada também a uma 
"desprogramação tática" das mídias locativas, uma "desnaturalização" da tecnologia que por sua vez abre possibilidades de reinvenção de suas funções e finalidades (Sperling et al, 2016, p. 854).

Para realizar os mapeamentos, foram utilizados dois tipos de fontes de dados: dados governamentais abertos (Open Data) e dados gerados por voluntários (Citizen Generated Data). Para a visualização dos dados e construção dos mapas, foram utilizadas plataformas abertas (Open Source/Free Software), tais como o software Gephi, utilizado para visualização e exploração de grafos e redes, e as plataformas de mapeamento Carto e Mapbox, para visualização de dados geolocalizados.

\section{RESULTADOS}

A seguir, apresentamos o resultado dos experimentos de pesquisa-ação.

\section{EXPERIMENTO 1: IR À FEIRA DE BIKERIO}

No Brasil, algumas administrações públicas estão adotando estratégias de dados abertos, em modelos de "prateleira de dados", que incluem a publicação de datasets abertos sobre informações públicas (Sieber \& Johnson, 2015). No caso da prefeitura do Rio de Janeiro, diversos conjuntos de dados com informações sobre diferentes serviços públicos estão sendo disponibilizados no portal Data.Rio. Uma tática para dar visibilidade a questões de interesse público que não são aparentes nos índices dos conjuntos de dados, é o cruzamento de conjuntos de dados de diferentes grupos e agências.

Nesse experimento, levantamos a questão da abrangência do serviço BikeRio, o sistema público de compartilhamento de bicicletas na cidade do Rio de Janeiro lançado em 2011 pela prefeitura do Rio de Janeiro em parceria com o Banco Itaú, e operado pela concessionária privada Serttel. O sistema disponibiliza 4000 bicicletas em diversas estações nos bairros da cidade.

Para avaliar a abrangência do serviço, decidimos comparar o dataset das estações do BikeRio, com o dataset das feiras livres da cidade, fazendo a seguinte pergunta: É possível ir à feira utilizando o BikeRio?

O primeiro passo foi consolidar os diferentes datasets em uma única tabela, utilizando a função "Consolidar" do software Microsoft Excel. Em seguida, os dados foram agregados na plataforma Carto, um sistema de informações geográficas que utiliza tecnologias de código aberto e dados abertos. Como pode ser observado na Figura 1, foi possível identificar que o sistema BikeRio ainda é restrito a bairros da Zona Sul do Rio de Janeiro. Apesar de ser considerado uma importante solução de mobilidade sustentável, o serviço BikeRio ainda carece da abrangência de serviços comunitários tradicionais como as feiras livres.

O resultado deste experimento pode ser consultado online no URL < http://qeweq.com/mapeamentos/fazerfeira-de-bike-rio/>.

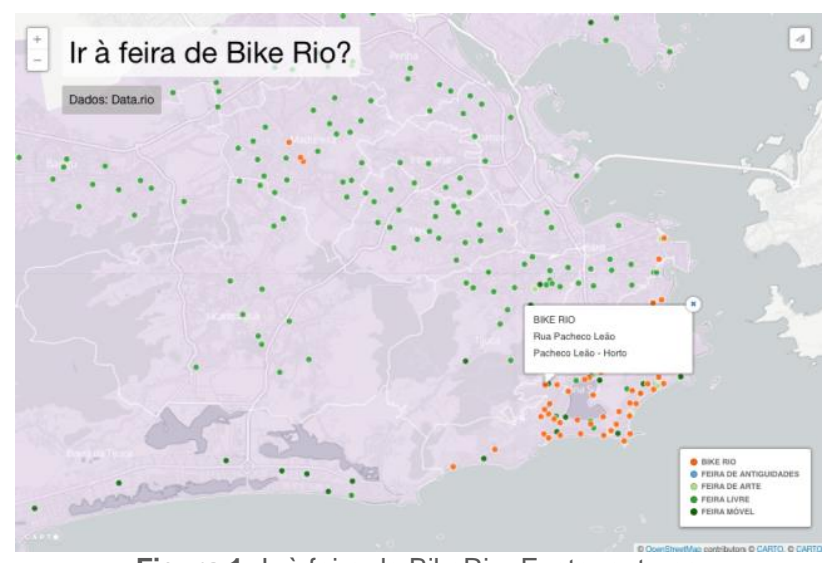

Figura 1: Ir à feira de BikeRio. Fonte: autores.

\section{EXPERIMENTO 2: POSTAIS APOSENTADOS}

Utilizando a mesma estratégia de cruzamento de datasets de diferentes grupos dados abertos, conforme descrito no experimento anterior, neste experimento decidimos comparar os conjuntos de dados dos pontos turísticos do Rio de Janeiro, divulgados em 2014 e 2016 no portal do Data.Rio, da Prefeitura do Rio de Janeiro.

Como pode ser observado na Figura 2, esse cruzamento de dados permitiu verificar como a realização da Copa do Mundo e dos Jogos Olímpicos mudou o panorama dos cartões postais da cidade. Equipamentos construídos especificamente para os Jogos Olímpicos, como o Museu do Amanhã e o Porto Maravilha foram agregados como pontos turísticos no conjunto de dados de 2016. Por outro lado, diversos pontos turísticos divulgados no conjunto de dados de 2014, como a rede de teatros públicos ou o Jardim Zoológico da cidade, deixaram de integrar a lista divulgada em 2016, demonstrando as prioridades da atual administração pública.

O resultado deste experimento pode ser consultado online no URL <http://qeweq.com/mapeamentos/pontosturisticos-do-rio/>

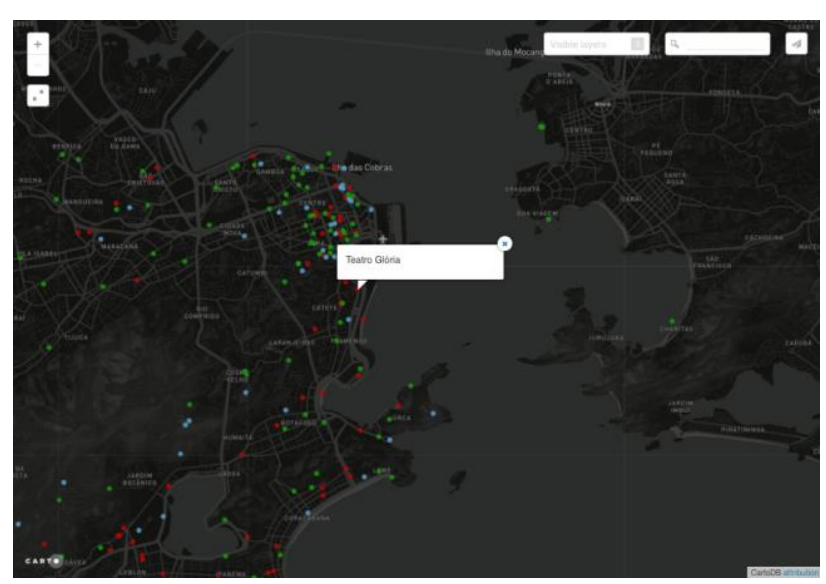

Figura 2: Postais aposentados. Fonte: autores.

\section{EXPERIMENTO 3: BICITRANCAS}

Em 2015, o Laboratório de Participação da Prefeitura do Rio de Janeiro (LAB.Rio) lançou o projeto Mapeando, com o objetivo de coletar dados sobre demandas de mobilidade da cidade. Entre 2015 e 2016, o Mapeando ofereceu aos cidadãos do Rio de Janeiro uma ferramenta de mapeamento colaborativo, onde usuários poderiam se cadastrar e geolocalizar demandas de mobilidade tais 
como: necessidades de pontos de ônibus, necessidades de faixa de pedestres, necessidades de semáforos, necessidades de ciclovias e bicicletários, entre outros. O acesso à plataforma foi disponibilizado em uma página Web, permitindo a interação tanto através de computadores de mesas como de dispositivos móveis. Ao experimentar a plataforma, percebemos que alguns usuários preenchiam dezenas de registros. Por exemplo, em poucos minutos, um usuário poderia registrar a demanda de mais de 100 bicicletários no meu bairro.

Neste experimento, procuramos inverter a abordagem de mapeamento. Em vez de marcar as demandas no mapa através dos computadores desktop que temos em casa ou no escritório, o mapeamento foi feito com o corpo, na rua, em uma deriva, utilizando smartphones para fazer registros fotográficos geolocalizados dos locais que concentram bicicletas trancadas em postes, grades, árvores e que determinam locais que de fato demandam a instalação de bicicletários.

Para realizar o mapeamento, optamos por extrair os dados de geolocalização que são armazenados nos metadados EXIF das fotografias que tiradas com nossos smartphones. A fotografias foram inicialmente armazenadas em um repositório Web. Em seguida foi utilizado um aplicativo open source chamado ExifTool para extrair os dados das coordenadas de geolocalização das imagens. Os dados foram agregados na plataforma Mapbox.

O experimento foi realizado durante uma caminhada de 1 (uma) hora na rua Nossa Senhora de Copacabana, em outubro de 2016 (Figura 3).

O resultado deste experimento, pode ser consultado online no URL <http://qeweq.com/mapeamentos/ bicitrancas/>.

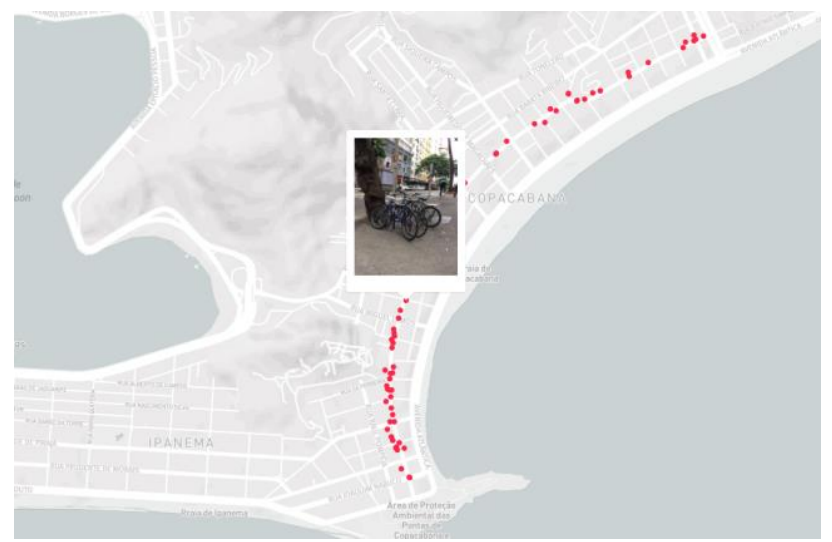

Figura 3: Bicitrancas. Fonte: autores.

\section{EXPERIMENTO 4: GAMBIARRAS}

Este experimento foi realizado em uma oficina de mapeamento colaborativo na Escola Superior de Desenho Industrial (Esdi), realizado em parceria com o professor Mauro Pinheiro, em novembro de 2016. Os participantes percorreram as ruas do centro da cidade do Rio de Janeiro procurando ocorrências de gambiarras, improvisos no espaço urbano, tais como puxadinhos em bancas, barracas de camelôs, cadeiras de porteiros prédios e vigias de rua, sinalizações de uso informal do espaço urbano, entre outros.
As ocorrências foram fotografadas com smartphones e publicadas na plataforma Twitter com a geolocalização ativada. Os dados e imagens foram extraídos da plataforma Twitter utilizando um script PHP para acessar a API REST do Twitter. Os dados foram agregados na plataforma Carto (Figuras 4 e 5).

O resultado deste experimento, pode ser consultado online no URL <http://qeweq.com/mapeamentos/ gambiarras/>.

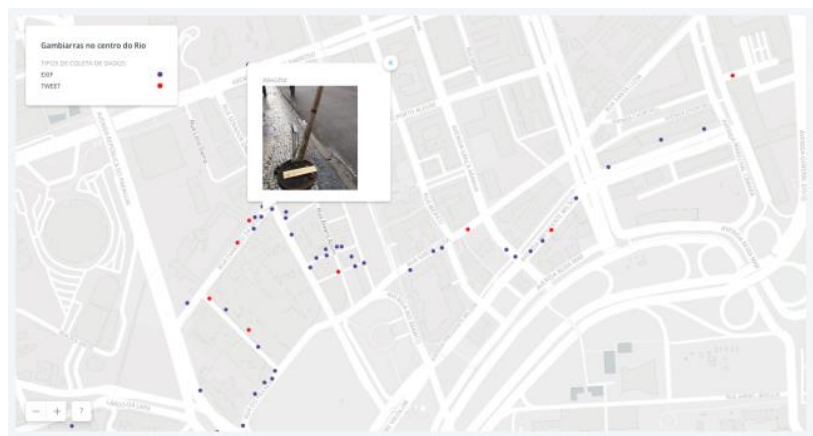

Figura 4: Gambiarras no centro do Rio. Fonte: autores.

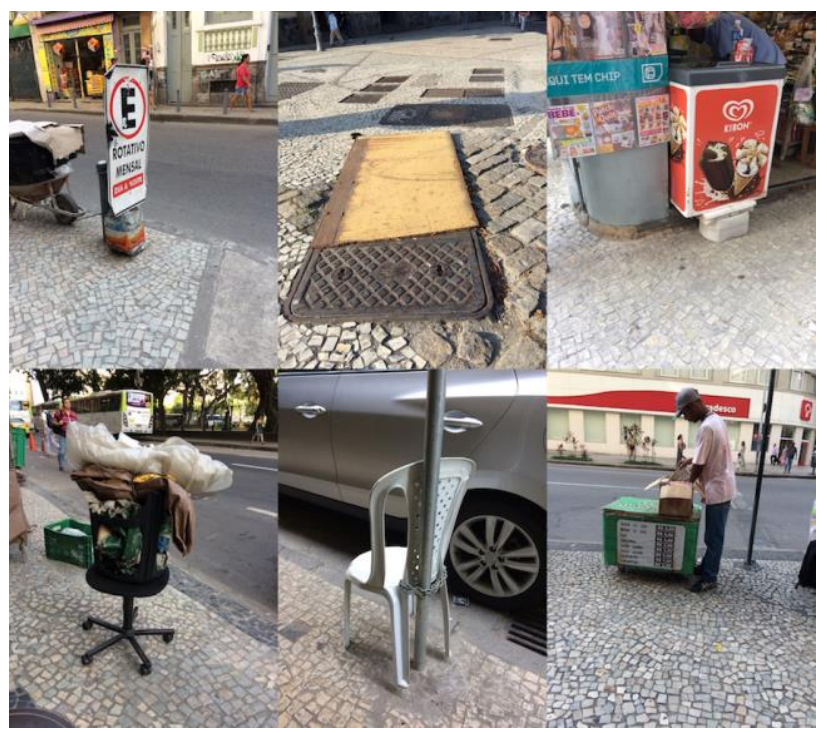

Figura 5: Gambiarras e improvisos urbanos. Fonte: autores.

\section{EXPERIMENTO 5: FRAGMENTOS DE PERCURSOS REINVENTADOS}

Neste experimento foi realizado um mapeamento colaborativo baseado em um jogo de micro-narrativas urbanas. O mapeamento foi produzido com o grupo Cotidiano e Mobilidade, para a exposição Coisa Pública, na Galeria Despina/Largo das Artes, no Rio de Janeiro em outubro de 2016.

Os percursos foram capturados através do aplicativo Strava, que constitui uma plataforma e rede social para esportistas que praticam corrida e ciclismo. A imagens com as micro-narrativas foram editadas de forma colaborativa através da plataforma Google Maps, e depois integrados à plataforma Mapbox (Figuras 6).

O resultado deste experimento, pode ser consultado online no URL <http://qeweq.com/mapeamentos/ fragmentos-de-percursos-reinventados/>. 


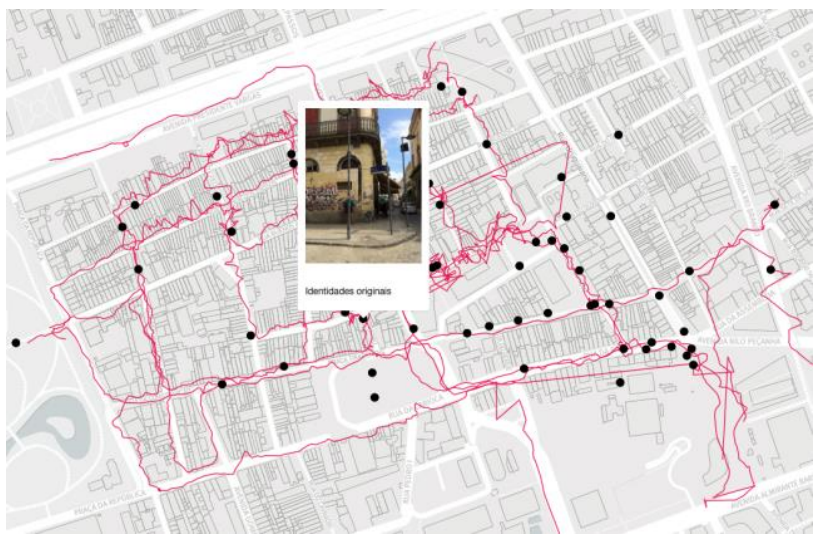

Figura 6: Fragmentos de percursos reinventados. Fonte: autores.

\section{EXPERIMENTO 6: JOGO DOS NÚMEROS}

Neste experimento, procuramos explorar duas táticas alternativas de mapeamento colaborativo: como extrair dados de mídias sociais e como gamificar a uma coleta de dados feita por voluntários.

Este experimento foi realizado em um workshop com a equipe do Laboratório de Arte Eletrônica da PUC-Rio, em junho de 2016, no escopo do projeto Gamificação e cartografias coletivas para cidadania digital em cidades inteligentes, contemplado pela Faperj em 2016.

Para o jogo de coleta de dados, os participantes receberam a missão de computar a soma de um número sorteado, encontrando os fatores da soma em ocorrências de números na paisagem urbana. Os números encontrados foram fotografados e postados no Twitter até a conclusão da soma.

Os percursos dos participantes foram coletados através do aplicativo Strava. As fotografias geolocalizadas como os números dos jogo foram extraídas da API do Twitter utilizando a plataforma Temboo. Os dados foram integrados na plataforma Mapbox.

O resultado deste experimento, pode ser consultado online no URL <http://qeweq.com/mapeamentos/ lae-numeros/>.

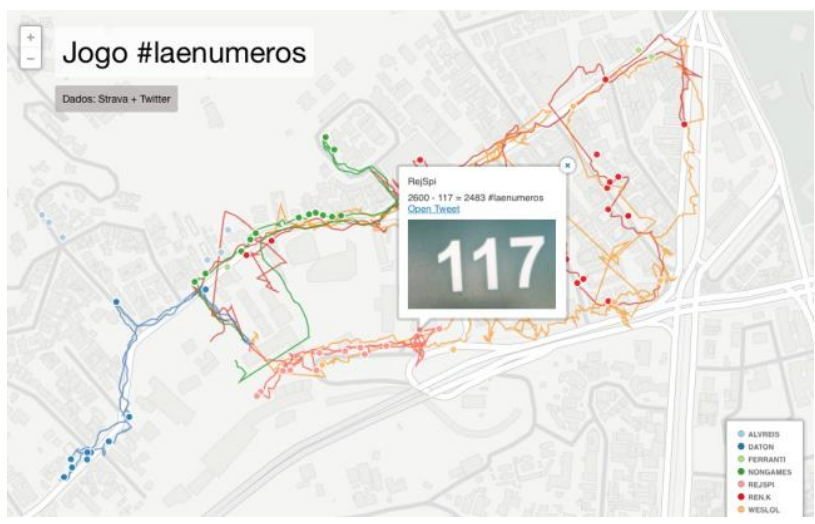

Figura 7: Jogo dos números. Fonte: autores.

\section{EXPERIMENTO 7. POLUIÇÃO DO AR NO CENTRO DO RIO}

O BeMap é um kit com sensores de hardware e código aberto, montado em um case produzido em impressoras $3 \mathrm{D}$, que pode ser acoplado ao guidom de bicicletas para monitorar condições de poluição do ar. O dispositivo foi desenvolvido por um time de estudantes de micro engenharia do Swiss Federal Institute of Technology em Lausanne, na Suíça. O grupo esteve no Brasil em setembro de 2016 para um workshop de mapeamento ambiental, organizado pela Swissnex Brasil, no Museu do Amanhã, no Rio de Janeiro.

Os participantes do workshop fizeram diferentes percursos de bicicleta no centro do Rio de Janeiro monitorando as condições de poluição do ar. Os dados coletados pelos sensores foram disponibilizados de forma aberta. O mapeamento apresentado na Figura 8 representa alguns dos percursos da minha participação no workshop. Os dados foram integrados na plataforma Carto.

O resultado deste experimento, pode ser consultado online no URL <http://qeweq.com/mapeamentos/ bemap/>.

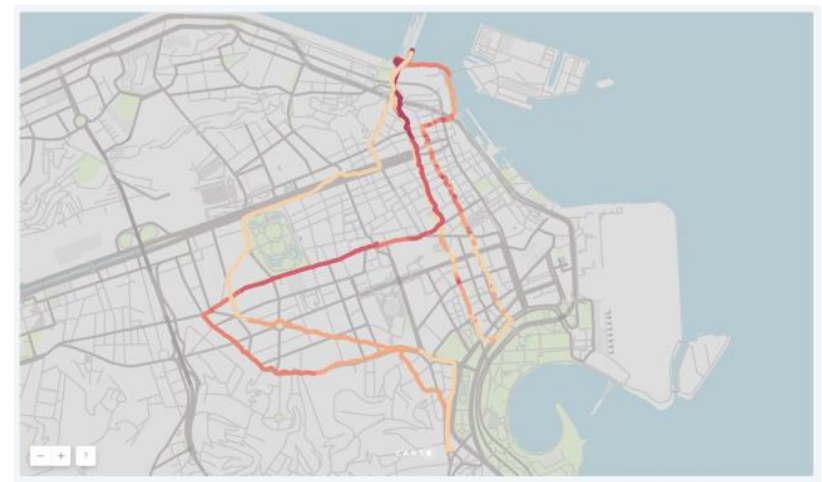

Figura 8: Poluição do ar em percurso de bicicleta no centro do Rio de Janeiro. Fonte: autores.

\section{EXPERIMENTO 8. CARTOGRAFIA DOS DESEJOS DOS GARIS}

A cartografia dos desejos dos garis foi um experimento sobre como tornar visível questões de interesse público. O experimento foi realizado no escopo na disciplina Práticas Criativas Colaborativas, oferecida pelas professoras Barbara Szaniecki e Talita Tibola, no Programa de Pós-graduação em Design da Escola Superior de Desenho Industrial (Esdi), e contou com a participação dos Garis envolvidos com os Círculos de Cidadania. O experimento teve como objetivo dar visibilidade aos discursos, sonhos e desejos da classe dos Garis, e foi realizado em um evento organizado pelos garis do Rio de Janeiro, em maio de 2016 no Parque Madureira.

A proposta da Barraca dos Desejos funcionou como um dispositivo sociotécnico - lúdico e aberto - para mediar uma coleta de dados, desejos, sonhos e reivindicações dos garis de forma criativa, tal como numa brincadeira, em que o designer assume o papel de barraqueiro e o visitante da barraca troca um doce por um desejo.

A experiência funcionou como um diálogo de design mediado por um jogo de participação (Brandt et al., 2008). Os desejos foram anotados em papel e depois estruturados em uma planilha de dados no software Microsoft Excel. Em seguida, utilizamos a ferramenta de código aberto Gephi, para desenvolver um gráfico de redes (network analysis) dos discursos subjacentes aos
5 
desejos dos garis. Cada desejo individual foi associado a duas categorias de nós/hubs: os atores dos desejos (Gari, Agente de Saúde Ambiental, Comlurb, Políticos, Sociedade); e os temas dos desejos (Sonhos, Direitos, Oportunidades, Mobilização).

O resultado deste experimento, pode ser consultado online no URL <http://qeweq.com/mapeamentos/ desejos-dos-garis/>.

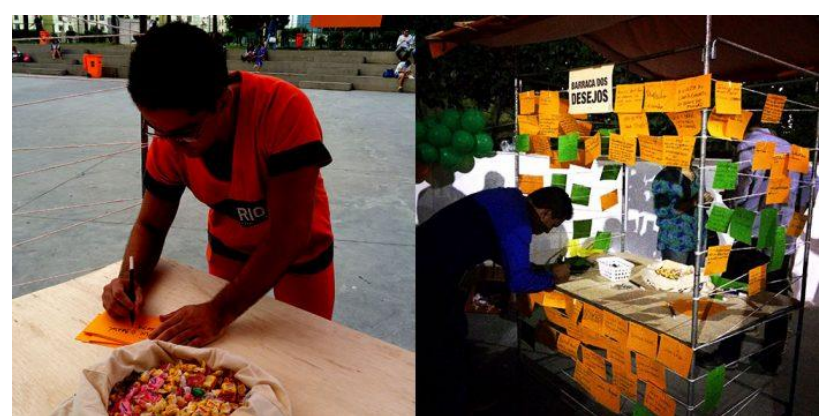

Figura 9: Garis e a barraca dos desejos. Fonte: autores.

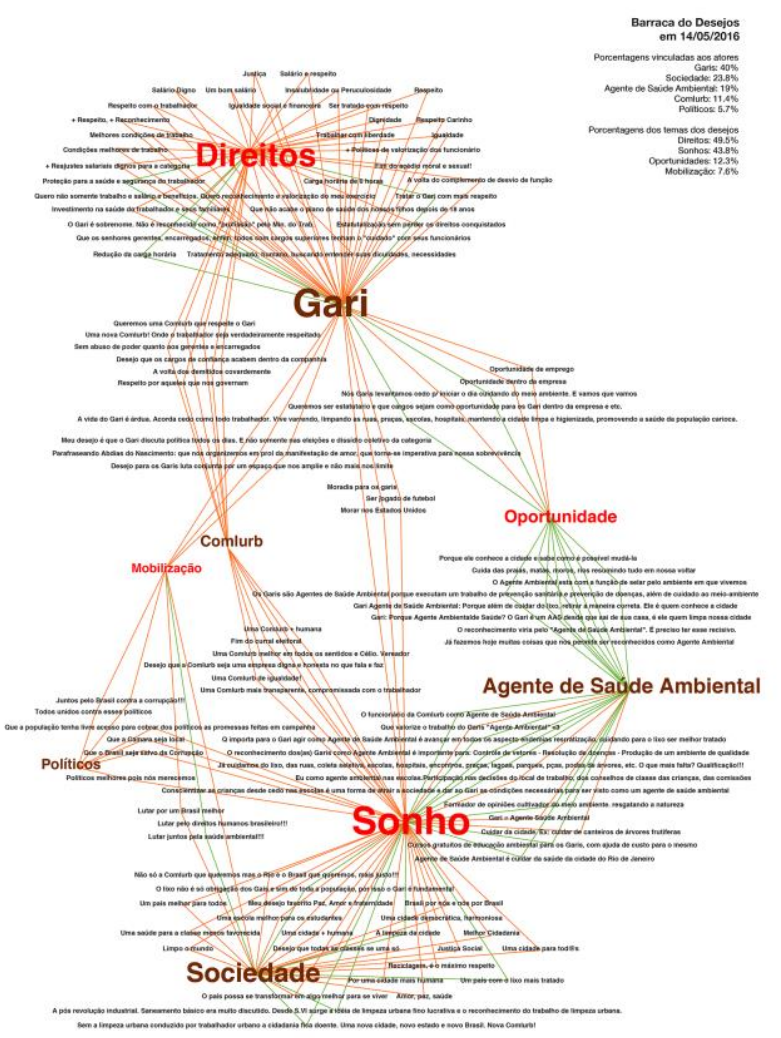

Figura 10: Cartografia do desejo dos garis. Fonte: autores.

\section{DISCUSSÃO}

Binder et al. (2015) sugerem modos de design democrático a partir de experimentos que permitam a expansão das práticas de design participativo e co-design para contextos mais amplos de "democracia em ação", abordando questões relacionadas a cidadania e participação pública através do engajamento direto com questões controversas, contradições, oposições e desacordos.
A partir dos experimentos de pesquisa-ação com mídias locativas e cartografia digital, foi possível explorar práticas abertas, democráticas, especulativas e críticas de design de mídias digitais, que podem dar visibilidade a questões de interesse público e apoiar processos de construção de sentidos sobre modos de vida mais sustentáveis.

A partir das táticas de deriva e desvio dos situacionistas, foi possível estabelecer uma experimentação e especulação sobre as questões sendo abordadas. A tática de deriva, dérive, nos levou a experimentar e construir a experiências urbanas a partir de deslocamentos e de jogos de leitura do espaço urbano. A tática de desvio, détournment, nos levou a uma apropriação de dados de bases governamentais abertas e de mídias sociais como o Twitter para podermos construir nossas próprias narrativas sobre questões de interesse público.

Ao utilizar tecnologias abertas, open source, constatamos uma potência democratizadora dessas tecnologias e práticas, uma vez que diminuem a barreira de entrado do custo de softwares proprietário. Ao mesmo tempo, essas tecnologias abertas guardam um ecossistema de documentação e colaboração, que estimula o aprendizado autônomo e participativo, à luz da filosofia Do It Yourself (Faça Você Mesmo). Todos os softwares utilizados dispõem de uma extensa documentação e de diversos tutoriais que são elaborados de forma aberta e colaborativa por toda a comunidade de desenvolvedores e usuários, além da disponibilidade de diversos foruns onde usuários menos experientes podem tirar dúvidas com especialistas, desenvolvedores e mesmo pares com mais experiência.

Com base nessas experiências, vislumbramos a possibilidade de uma abordagem design mais aberta a processos democráticos, participativos, críticos e especulativos, com uma atitude mais ativista, mais hacktivista," que abre o campo do design - assim como das outras disciplinas centradas na cultura do projeto, como a arquitetura e a engenharia - para processos de inovação social e produção comum, em contraposição às práticas associadas a processos de industrialização e consumo.

Mais ainda, essas práticas envolvem o design com a infraestruturação de espaços de interação sobre as controvérsias que formam a coisa pública (Ehn, 2008; Bjögvinsson et al, 2012).

Essas práticas com mídias locativas e a democratização das tecnologias de geoprocessamento, abrem também o território para uma série de iniciativas no campo tecnologias cívicas e da ciência cidadã e das plataformas de inovação social digital (Pereira Jr., 2017). Cada vez mais organizações não governamentais, coletivos informais, startups de empreendedorismo social, estão lançando mão dessas tecnologias para construir sentidos sobre questões de interesse público, em prol de uma sociedade mais justa e democrática, dando oportunidade de participação e voz para as pessoas, cidadãos e comunidades em cenários de governo aberto e de ação comunitária. 
Uma nova cultura de design, aberta, colaborativa, ativista e participativa será necessária para promover a transição para modos de vida mais sustentáveis, para construção de uma sociedade mais justa e inclusiva. Assim poderemos vislumbrar novas formas de pensar e de fazer design, longe do determinismo e da eficiência industrial e mais perto da ação e da transformação social.

\section{REFERÊNCIAS}

Binder, T.; Brandt, E.; Halse, J. (2015). Democratic Design Experiments: Between Parliament and Laboratory. CoDesign: International Journal of CoCreation in Design and the Arts, v. 11, n. 3-4,

Bjögvinsson, E.; Ehn, P.; \& Hillgren, P. (2012) Design Things and Design Thinking: Contemporary Participatory Design Challenges. Design Issues, v. 28, n. 3, 101-116.

Brandt, E; Messeter, J., Binder, T. (2008) Formatting Design Dialogues: Games and Participation. In: Binder T, Brandt $\mathrm{E}$ and Gregory J (Guest editors), CoDesign: International Journal of CoCreation in Design and the Arts, v. 4, n. 1, 5164.

Crampton, J. (2009) Cartography: maps 2.0. Progress in Human Geography, v.33, n.1, p. 91-100.

Crampton, J.; John Krygier, J. (2010). An Introduction to Critical Cartography. In: ACME: An International E-Journal for Critical Geographies, 4 (1), 11-33

Dewey, J. (2007) The Public and Its Problems. Athens, OH: Swallow Press Books, Henry Holt \& Company.

Debord, G. (1958) La théorie de la dérive. Internationale Situationniste \#2. Disponível em: <http://ptbr.protopia.wikia.com/wiki/Teoria_da_Deriva>. Acessado em: $25 / 06 / 2018$

Debord, G.; Wolman, G. (1956) Mode d'emploi du détournement. Les Lèvres Nues \#8. 1956. Disponível em: <http://sami.is.free.fr/Oeuvres/debord_wolman_mode_emploi _detournement.html>. Acessado em: 25/06/2018

Disalvo, C. (2012) Adversarial Design. Kindle Edition. Cambridge, MA: The MIT Press.

Disalvo, C. (2009) Design and the Construction of Publics. Design Issues, v. 25, n. 1.

Dunne, A.; Raby, F. (2013) Speculative everything: design, fiction and social dreaming. Cambridge, London: The MIT Press.

Ehn, P. (2008) Participation in Design Things. In: PArticipatory Design Conference, 08, Bloomington, 2008 Proceedings... Bloomington, Indiana: ACM Press, p. 92-101.

Hemment, D.; Thompson, B,; Vicente, J.; Cooper, R. (Org.). (2013). Digital Public Spaces. FutureEverything Publications.
Irwin, T.; Kossof, G.; Tonkinwise, C.; Scupelli, P. (2015) Transition Design. Pittsburgh, PA, Carnegie Mellon Design.

Latour, B. (2005) Reassembling the Social: An Introduction to Actor-Network-Theory. Oxford University Press.

Latour, B.; Weibel, P. (2005) Making Things Public: Atmospheres of Democracy. Cambridge, MA: MIT Press.

Lemos, A. (2008). Mídias locativas e territórios informacionais. Carnet de Notes.

Levy, P. (1998). A inteligência coletiva. Por uma antropologia do Ciberespaço. Loyola, 1998.

Manzini, E. (2015). Design When Everybody Designs: An Introduction to Design for Social Innovation. Massachusets: MIT Press.

Mcquire, S. (2006). The politics of public space in the media city. First Monday. Disponível em: <http://www.firstmonday. org/issues/special11_2/mcquire/ index.html>. Acessado em: 25/06/2018.

Pereira Jr, C.; Holanda, G.; Spitz, R. (2016). Crowdmapping e mapeamento colaborativo em iniciativas de inovação social no Brasil. In: Proceedings of SIGraDi 2016: Crowdthinking, XX Congreso de La Sociedad Iberoamericana de Gráfica Digital. Blucher Design Proceedings. Novembro 2016 vol. 3 num. 1. ISSN: 2318-6968

Pereira Jr., C. (2017). Tecnologias cívicas e inovação social digital: desafios para o design nos novos territórios de participação cidadã. Tese (Doutorado e Design) Departamento de Artes e Design, Pontifícia Universidade Católica do Rio de Janeiro. Rio de Janeiro, 159 p. 2017

Sestini, F. (2012). Collective awareness platforms: Engines for sustainability and ethics. IEEE Technology and Society Magazine, v. 31, n.4, 54-62. Disponível em: $<$ http://caps2020.eu/wpcontent/uploads/2013/11/CollectiveAwareness PlatformsEngineforSustainabilityandEthics-1.pdf>. Acessado em: 25/06/2018.

Santaella, L. (2008). A Estética políticas das mídias locativas. In: Nomadas. no. 28. abril 2008. Universidad Central Colombia.

Souza e Silva, A. (2006) From Cyber to Hybrid: Mobile Technologies as Interfaces of Hybrid Spaces. Space and Culture, v. 9, n. 3, 261-278.

Sperling, D.; Santos, F.; Costa, L.; Lopes, R. (2016) Jogo e deriva com mídias (des)locativas In: SIGraDi 2016, XX Congress of the Iberoamerican Society of Digital Graphics 911, November, 2016 - Buenos Aires, Argentina

Tuters, M.; Varnelis, K. (2006). Beyond locative media. Disponível

em: <http://networkedpublics.org/locative_media/beyond_locative media.html>. Acessado em: 25/06/2018. 